\title{
Solid-State DC Voltage Standard Calibrations
}

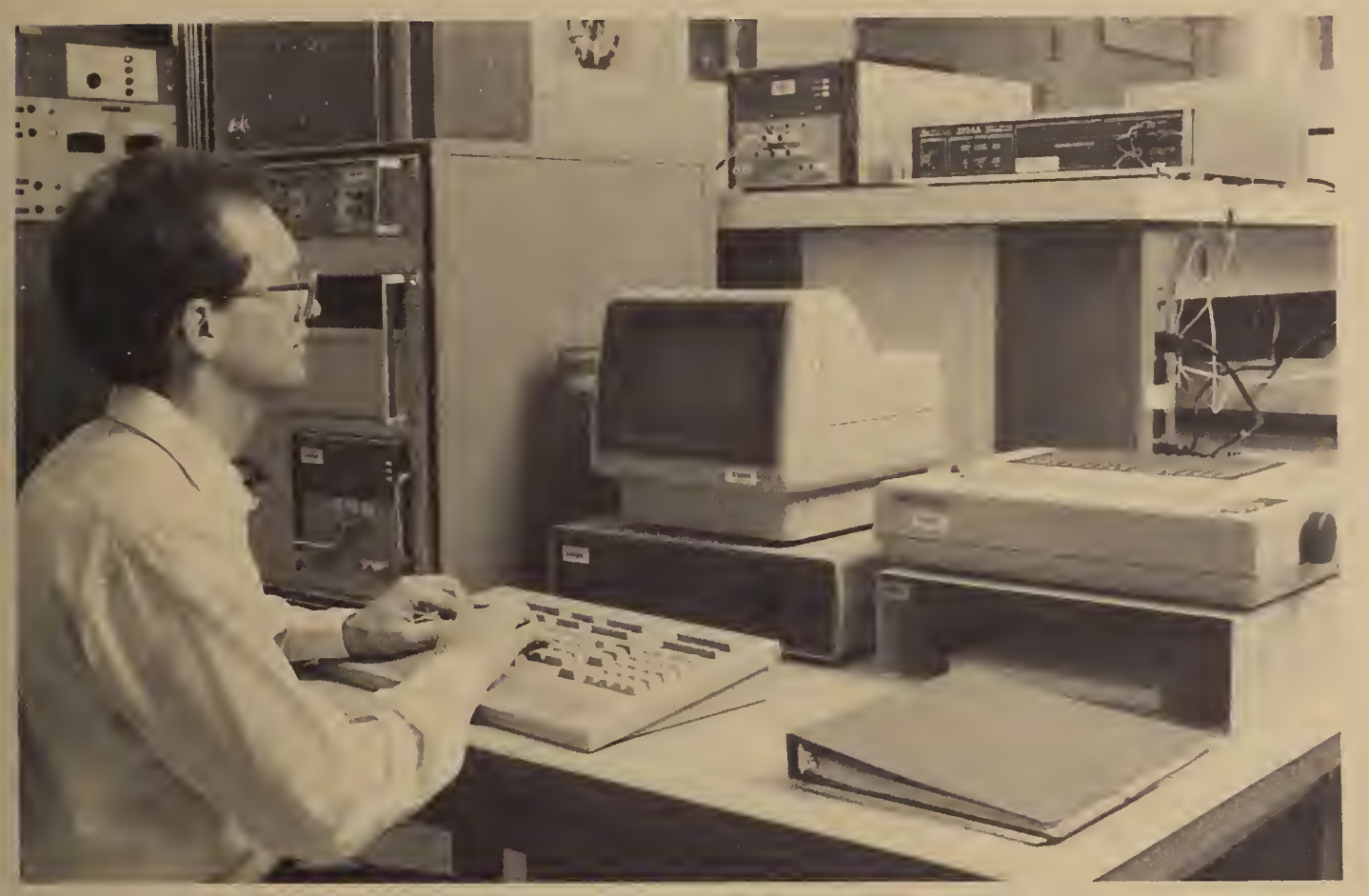

NBS

Special

Publication

250-28

Bruce F. Fleld

U.S. Department of Commerce

National Bureau of Standards 


\section{Center for Basic Standards}

The Center for Basic Standards develops and maintains the scientific competences and laboratory facilities necessary to preserve and continue to refine the base physical quantities upon which the Nation's measurement system is constructed. The Center is responsible for the standards of voltage, current, resistance and impedance, temperature, vacuum, leak rate, pressure, mass, length, time and frequency. The Center collaborates closely with the standardizing laboratories of other countries to ensure that measures used in international trade are fully compatible. The Center also performs research at the frontiers of physics in order to improve measurement capability and quantitative understanding of basic physical processes that underlie measurement science.

\section{Electricity Dlvision}

Maintains and improves the national standards of electrical measurement; conducts experiments to realize the electrical units in terms of the mechanical units; develops stable electrical standards and improved methods for the dissemination of the units of electrical measurement; determines fundamental physical constants related to electrical units; develops instrumentation for precise electrical measurements directly referenced to the national standards; implements techniques for their use and puts them into practical applications; assists in applying scientific and technological development to measurement problems, especially in other areas of NBS research.

\section{Temperature and Pressure Division}

Maintains and improves the national standards of temperature and pressure; conducts research towards the development of new concepts for these standards; calibrates practical standards for the U.S. scientific and technical community in terms of the primary standards; develops methods and devices to assist user groups in the assessment and enhancement of the accuracy of their measurements of temperature and pressure; prepares and promulgates evaluations and descriptions of temperature and pressure measurement processes; coordinates these standards and measurement methods nationally and internationally; and determines the accuracy of the national standards of temperature and pressure with respect to fundamental thermodynamic relations.

\section{Length and Mass Divislon}

Develops and uses the competence necessary to implement a more accurate measurement system for length and mass; applies research, utilizing the most advanced technology available, to the improvement of our present standards and devises new standards and new methods for their transfer.

\section{Time and Frequency Division}

Maintains, develops and improves the national standards for the unit of time, the unit of frequency, and time scales based on these standards; carries out research in areas of importance to the further fundamental improvement of frequency standards and their applications focusing on microwave and laser devices, atomic and molecular resonances, and the measurement of fundamental physical phenomena and constants; adapts time and frequency standard devices and concepts to special scientific and technological demands; develops time and frequency measurement methods in the radiofrequency, microwave, infrared, and visible radiation regions; coordinates the NBS time scales with international time scales and the time scales maintained by the United States Naval Observatory; collaborates with national and international organizations in the development of improved methods for the measurement of time related quantities; operates time and frequency dissemination services, such as radio stations and broadcasts, for the purpose of traceability to the national standards of time and frequency.

\section{Quantum Physics Division}

Engages in research in atomic and molecular physics at the forefront of the field, and performs basic, highly accurate measurements and theoretical analyses that help establish a reliable foundation for scientific and technological measurement and data.

\section{Quantum Metrology Division}

Engages in forefront research in quantum metrology; contributes to new determinations of the fundamental physical constants, and the extension and refinement of the electromagnetic scale and devises, where possible, tests of basic symmetries and invariances. 


\section{NBS MEASUREMENT SERVICES: Solid-State DC Voltage Standard Calibrations}

Bruce F. Field

Center for Basic Standards

National Measurement Laboratory

National Bureau of Standards

Gaithersburg, MD 20899

January 1988

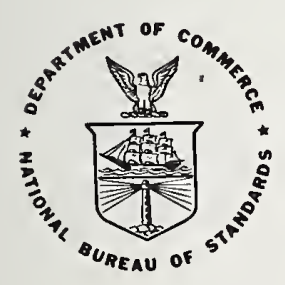

U.S. DEPARTMENT OF COMMERCE, C. William Verity, Secretary NATIONAL BUREAU OF STANDARDS, Ernest Ambler, Director 
Library of Congress Catalog Card Number: 87-619904

National Bureau of Standards Special Publication 250-28

Natl. Bur. Stand. (U.S.), Spec. Publ. 250-28, 39 pages (Jan. 1988)

CODEN: XNBSAV

U.S. GOVERNMENT PRINTING OFFICE

WASHINGTON: 1988

For sale by the Superintendent of Documents, U.S. Government Printing Office, Washington, DC 20402-9325 


\section{PREFACE}

Calibrations and related measurement services of the National Bureau of standards provide the means for makers and users of measuring tools to achieve levels of measurement accuracy that are necessary to attain quality, productivity and competitiveness. These requirements include the highest levels of accuracy that are possible on the basis of the most modern advances in science and technology as well as the levels of accuracy that are necessary in the routine production of goods and services. More than 300 different calibrations, measurement assurance services and special tests are available from NBS to support the activities of public and private organizations. These services enable users to link their measurements to the reference standards maintained by NBS and, thereby, to the measurement systems of other countries throughout the world. NBS special Publication 250, NBS Calibration Services Users Guide, describes the calibrations and related services that are offered, provides essential information for placing orders for these services and identifies expert persons to be contacted for technical assistance.

NBS Special Publication 250 has recently been expanded by the addition of supplementary publications that provide detailed technical descriptions of specific NBS calibration services and, together with the NBS Calibration Services Users Guide, they constitute a topical series. Each technical supplement on a particular calibration service includes:

- specifications for the service

o design philosophy and theory

o description of the NBS measurement system

- NBS operational procedures

o measurement uncertainty assessment

error budget

systematic error

random errors

- NBS internal quality control procedures 
The new publications will present more technical detail than the information that can be included in NBS Reports of Calibration. In general they will also provide more detail than past publications in the scientific and technical litterature; such publications, when they exist, tend to focus upon a particular element of the topic and related elements may have been published in different places at different times. The new series will integrate the description of NBS calibration technologies in a form that is more readily accessible and more useful to the technical user.

The present publication, SP 250-28, NBS Measurement Services: Solid-State DC Voltage Standard Calibrations, by Bruce F. Field, is one of approximately 20 documents in the new series published or in preparation by the Center for Basic Standards. It describes calibration technology and procedures utilized in connection with NBS Service Identification Numbers from 53110 to 53150 listed in the NBS Calibration Services Users Guide. Inquiries concerning the contents of these documents may be directed to the author or to one of the technical contact persons identified in the Users Guide (SP-250).

Suggestions for improving the effectiveness and usefulness of the new series would be very much appreciated at NBS. Likewise, suggestions concerning the need for new calibration services, special tests and measurement assurance programs are always welcome.

Joe Simmons, Acting Chief Office of Physical Measurement Services

Helmut Hellwig, Acting Director

Center for Basic Standards 


\section{Table of Contents}

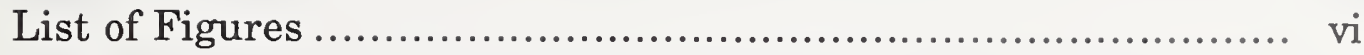

List of Tables ...................................................... vi

Abstract............................................................ 1

1. Introduction........................................................ 1

2. Description of Service ............................................... 2

Types of Standards Accepted for Calibration................... 2

Shipment of Standards .......................................... 2

Calibration Procedures....................................... 2

3. Calibration Apparatus and Measurement Approach .............. 3

System Description............................................. 3

Zener Reference...................................... 4

Resistive Divider ........................................ 4

Scanner.................................................. 4

Digital Voltmeter............................................ 5

Working Group C ............................................ 5

Measurement Process .......................................... 5

Measurement Theory ...................................... 6

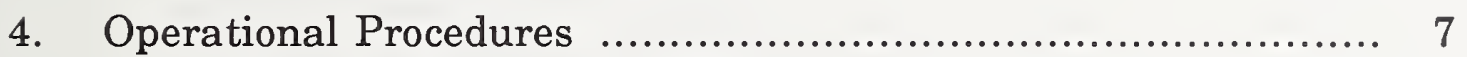

Client Standards Handling ............................... 7

Daily Procedures................................................ 8

Calibration of Working Group C ........................ 8

Calibration of Solid-State Standards .................. 8

Analysis of the Daily Data .............................. 9

5. Assignment of the Final Value ..................................... 12

Uncertainty................................................ 13

Explanation of Table Items $\ldots \ldots \ldots \ldots \ldots \ldots \ldots \ldots \ldots \ldots \ldots \ldots$

6. Quality Control Procedures ............................................ 15

Measurement System Verification.......................... 15

Client Standard Evaluation................................. 17

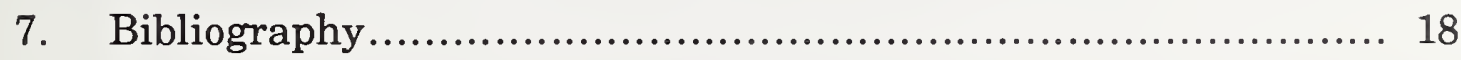

Appendices

A Report of Calibration ........................................... 19

B Measurement Software ...................................... 22 


\section{List of Figures}

Figure

page

1. Block diagram of the dc voltage measuring system............ 3

2. Simplified wiring diagram of the measuring system set up to compare a standard-under-test to the calibrated resistive divider (Transfer Reference) ........................ 6

3a. Page 1 of a typical daily printout from the measurement program READZEN............................................... 10

3b. Page 2 of a typical daily printout from the measurement program READZEN.

4. The three voltage outputs of a typical solid-state standard sent to NBS for calibration

5. Ten volt output of a check standard as measured by the system

\section{List of Tables}

page

Table I. Uncertainties in the Final Assigned Value 


\title{
NBS MEASUREMENT SERVICES: SOLID-STATE DC VOLTAGE STANDARD CALIBRATIONS
}

\author{
Bruce F. Field
}

\begin{abstract}
This document describes the procedures used at NBS to calibrate solid-state dc voltage standards in terms of the U.S. Legal Volt. The process involves calibrating client standards at NBS approximately 10 times over a two week period. The operational procedures and apparatus used to compare the client standards to the U.S. Legal Volt are discussed in detail.
\end{abstract}

\section{Introduction}

DC voltage standards based on solid-state devices are now available with stabilities approaching $1 \mathrm{ppm} /$ year. Such voltage standards can be used to maintain and disseminate (transfer) a laboratory unit of voltage with accuracies approaching those obtainable with saturated standard cells. Presently-available voltage standards"contain at least one (and sometimes more) Zener diode reference devices which develop a voltage that is scaled using internal resistive dividers and low-noise amplifiers to produce a range of output voltages from 1 to $10 \mathrm{~V}$. These standards typically have their best accuracy at some voltage other than the 1.01-V level of standard cells. NBS has developed a calibration service based on a specialized measuring system that automatically compares the output of any arbitrary voltage source, within the voltage range of one to ten volts, to a $1.018-\mathrm{V}$ reference standard.

Solid-state voltage standards that are accepted for calibration must be complete instruments, must be powered by the ac line or internal batteries, and must continuously produce one or more stable voltages. Such standards, when sent to NBS, are allowed to stabilize, and then are directly compared to NBS standards which are in turn calibrated in terms of the U.S. Legal Volt. Typically ten comparisons are made (once each working day) over a two week period. At the conclusion of the test a report is issued with a statement of the values of the voltage outputs of the standard and the estimated uncertainties for the values while the standard was at NBS. No additional uncertainty is included for transportation effects, long term drifts of the outputs, or measurement errors in the client's laboratory.

The calibration of solid-state standards is closely tied to, and dependent on, the calibration of working groups of standard cells. The reader is thus referred to reference 1, NBS SP250-24, NBS Measurement Services: Standard Cell Calibrations, for a complete explanation of the apparatus and procedures used for the calibration of standard cells. 


\section{Description of Service}

\section{Types of Standards Accepted for Calibration}

NBS offers a calibration service for solid-state voltage standards that are complete functioning standards which continuously produce the output voltages to be measured. We do not accept bare reference devices or modules that require a stabilized power supply for operation. Also not accepted are instruments with multiple outputs that must be manually switched to one set of output terminals. Each output voltage to be measured must be continuously available at a set of terminals dedicated to only that output. A potentiometric (non-loading) method is used for the measurement of the standards so there is no requirement that the standard be capable of delivering current to the measuring system. Standards having output resistances as high as $1 \mathrm{k} \Omega$ can be accurately measured.

\section{Shipment of Standards}

Solid-state standards may be carried to NBS by hand, or shipped to NBS by common carrier; arrangements can be made with a local delivery service for pickup and delivery to local airports. Standards may be shipped under battery power to maintain temperature control and/or to power the reference device, or they may be shipped with all power turned off. If they are shipped with the power turned off we have observed that a short (2-3 days) settling time is occasionally necessary before high-accuracy measurements can be started.

\section{Calibration Procedures}

Most solid-state standards operate with the reference device in a temperature-controlled oven. The temperature of the oven is recorded when the standard is first put on test (if the standard contains a temperature measuring device), but unless specially requested, the temperature of the oven is not measured or recorded during the remainder of the test.

Routine calibrations of solid-state standards typically take 2 to 3 weeks to complete. The voltages are read daily for a period of ten working days. After ten readings the data are reviewed by NBS personnel and if the stability and day-to-day scatter of the outputs are within acceptable limits, a calibration report is issued. If the measured voltages fluctuated or drifted unduly during the measurement period, the report will reflect these circumstances. In some cases additional measurements may be taken to confirm the existence of a problem. If the standard exhibits an initial drift but later becomes stable (indicating a transportation problem), additional measurements will be taken until at least ten stable readings have been obtained. Only in rare circumstances would more than twenty measurements be taken; if the standard has not stabilized by that time it is likely that it is de- 
fective. Only the stable readings are used for the final values in the calibration report.

\section{Calibration Apparatus and Measurement Approach}

\section{System Description}

The system used at NBS to calibrate solid-state voltage standards is specially designed; it employs a potentiometric method to measure the standard which allows voltage measurements to be made without loading the standard. (This system is also described in reference 2). The system is basically a scaling device for comparing arbitrary voltage standards to $1.018-\mathrm{V}$ standard cells. It will measure any dc voltage in the range from 0 to $10 \mathrm{~V}$, and has input channels for up to 54 unknown standards.

The system is also capable of making high-accuracy standard cell comparisons. Standard cells may be connected to the input channels of the scanner in place of (or in addition to) solid-state standards and these cells may be intercompared with one another.

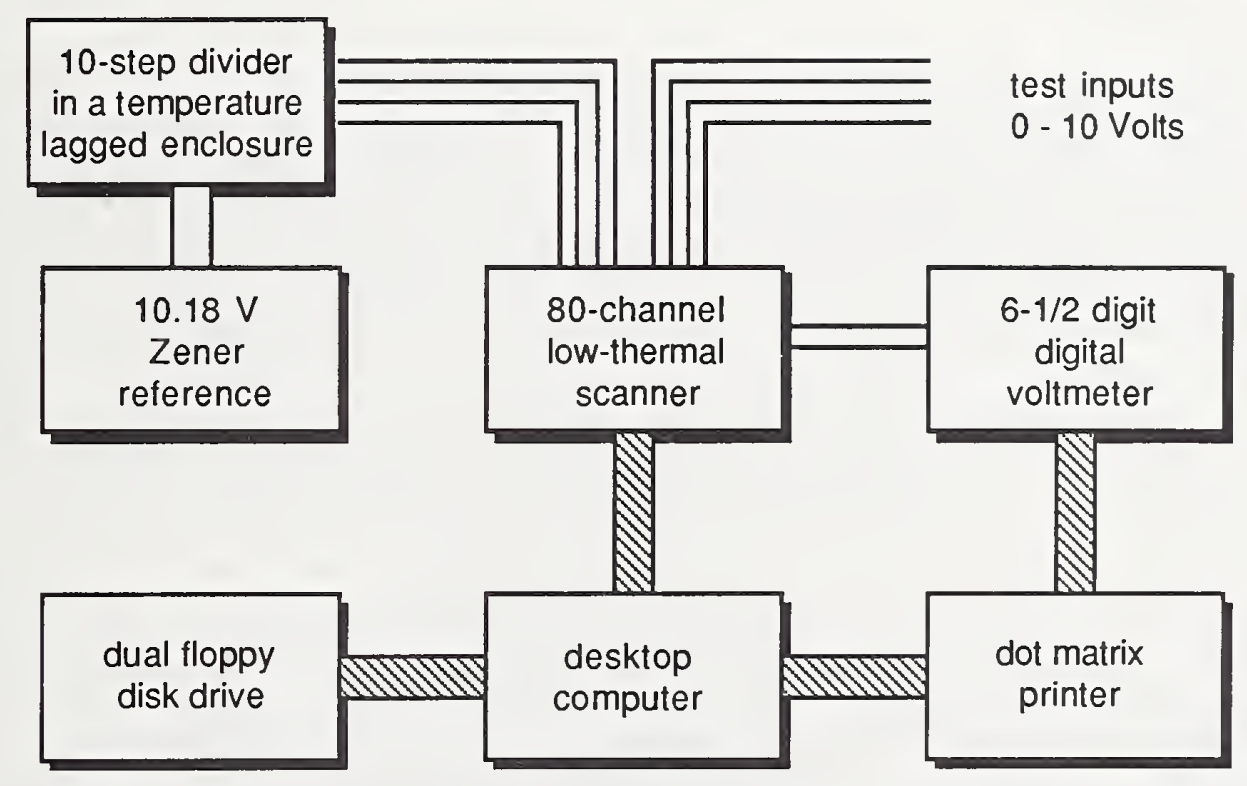

Fig. 1. Block diagram of the dc voltage measuring system.

Figure 1 is a simplified block diagram of the measurement system. It includes a modified 10.18-V Zener reference, a 10-step resistive divider consisting of 10 nominally equal $250-\Omega$ resistors, a low-thermal-emf crossbar scanner, a 6-1/2 digit digital voltmeter (DVM), and a desktop computer. The scanner, voltmeter, disk drive, and printer are connected to the computer with an IEEE-488 bus system. Not shown in the figure is an addition- 
al connection to a $16 \mathrm{Mbyte}$ hard disk which is common to several measuring systems in the laboratory and which is used for program and data storage. The floppy disk system is used for backup data storage in addition to the main storage on the hard disk.

Also not shown in Fig. 1 is the group of four saturated standard cells used as a reference for the system (Working Group C). All solid-state voltage measurements are expressed as a numerical ratio times the mean emf of these four cells. These cells in turn are calibrated daily in terms of the U.S. Legal Volt using standard NBS procedures [1].

\section{Zener Reference}

The Zener reference is a commercial Zener standard that has been modified to produce $10.1817 \mathrm{~V}$ rather than the $10 \mathrm{~V}$ normally supplied. With 16 AWG wire connecting the standard and the resistive divider the voltage at the divider is very close to $10.181 \mathrm{~V}$, approximately ten times the voltage of a saturated standard cell at $30{ }^{\circ} \mathrm{C}$. Interactions between the Zener reference and the other parts of the measuring system (notably the DVM) are negligible even when the standard is plugged into the ac power lines. The Zener reference is operated on ac power for all the measurements.

\section{Resistive Divider}

The resistive divider driven by the Zener reference consists of 10 nominally equal, stable $250-\Omega$ wire-wound resistors. The $250 \Omega$ choice is a compromise between reducing the resistance to minimize the effects of leakage resistances and increasing the load current that must be supplied by the Zener reference. The resistors are selected for matched temperature coefficients; all the coefficients are within $\pm 1 \mathrm{ppm} /{ }^{\circ} \mathrm{C}$ of one another. The resistors are mounted in a thick-walled aluminum box for temperature lagging. During a measurement sequence the individual resistors typically change value less than $0.03 \mathrm{ppm}$ with respect to the total divider resistance.

\section{Scanner}

The scanner used to select the voltage inputs is a modified crossbar switch identical to the VTP scanner described in reference 1. It has 802 -wire input channels and uses latching relays to reduce the thermal emfs within the switches. The scanner is wired so that any two of the 80 channels may be selected by the computer and connected together in series opposition with the difference voltage presented to the DVM. By selecting the two channels in reverse order the voltage difference with opposite polarity is presented to the DVM. The unresolved thermal emfs of the scanner have been periodically measured and are less than $0.015 \mu \mathrm{V}$ per switch. Twenty of the channels are used for the resistive divider, four channels are used for the reference standard cells, and two channels are reserved for crossbar thermal tests, leaving 54 channels available for unknown standards. 
A $6-1 / 2$ digit DVM with $0.1 \mu \mathrm{V}$ resolution on the $0.1-\mathrm{V}$ range is used as the system voltmeter. The voltmeter is programmed and read by the computer. All voltages are measured by the DVM in both the forward and reverse direction to cancel offset voltages in the DVM. The $0.1-\mathrm{V}$ range is used when measuring microvolt level voltages associated with standard cell differences, and an integration time of $9 \mathrm{~s}$ for each polarity yields a random measurement uncertainty of $0.03 \mu \mathrm{V}(1 \mathrm{~s})$ for a single measurement. For all measurements of solid-state standards, except at the 1.018-V level, the voltmeter is calibrated and used on the $1-\mathrm{V}$ range.

\section{Working Group C}

Working Group C consists of four saturated standard cells housed in a commercial temperature-regulated enclosure. The enclosure contains an internal thermistor and Wheatstone bridge for measurement of the cell temperatures with a resolution of $0.001{ }^{\circ} \mathrm{C}$. The enclosure is powered from a regulated $12 \mathrm{~V} \mathrm{dc}$ power supply to minimize any effects of a changing ac line voltage.

\section{Measurement Process}

The general measurement procedure is to 1) self-calibrate the system using Working Group C, 2) compare the unknown solid-state standards to the calibrated system, and 3) self-calibrate the system again to make sure no significant drifts have occurred. The exact procedure is controlled by a measurement procedure file (RUNFILE) which is executed by the computer. The measurement procedure file is created and modified daily by the operator as necessary.

Figure 2 shows some critical parts of the measuring system in more detail. The modified $10.18-\mathrm{V}$ Zener reference is permanently connected to the resistive divider; this combination (the Transfer Reference) is considered to be a stable voltage source with ten series-connected $1.018 \mathrm{~V}$ outputs. The Transfer Reference is calibrated by comparing the voltage drop across each resistor to each cell in Working Group $\mathrm{C}$, measuring the microvolt-level difference voltages with the digital voltmeter. All four Working Group C cells are compared to the ten Transfer Reference voltages for a total of 40 measurements which results in a redundant set of measurements. [1] By referencing each output tap to the bottom tap, the Transfer Reference can be used as a source of ten calibrated voltages from $0 \mathrm{~V}$ to $10.18 \mathrm{~V}$ in steps of $1.018 \mathrm{~V}$. Then (as shown in Fig. 2) the output voltage developed across $\mathrm{N}$ of the divider resistors is compared to the voltage of the unknown standardunder-test using the DVM. $\mathrm{N}$ is chosen to minimize the magnitude of the DVM reading. All the solid-state standards to be measured are compared in turn to the divider tap appropriate for that standard. Then the Transfer Reference voltages are compared a second time to the standard cell voltages after all the standards-under-test measurements have been completed. The 
second "calibration" of the Transfer Reference reduces the error caused by any drift in the Reference during the measurements. The low-thermal scanner switch is used to connect the standard cells and solid-state standards to the measurement system.

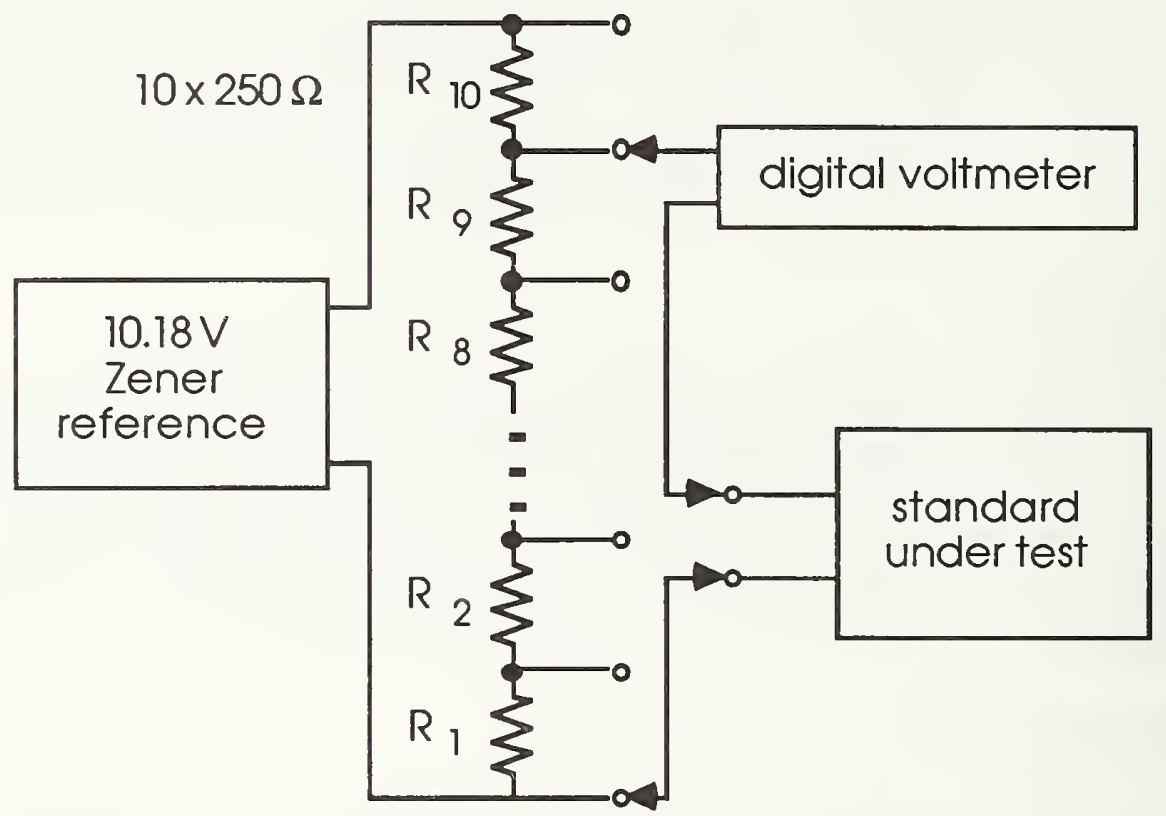

Fig. 2. Simplified wiring diagram of the measuring system set up to compare a standard-under-test to the calibrated resistive divider (Transfer Reference). Not shown is the low-thermal crossbar selector switch.

\section{Measurement Theory}

With this system the digital voltmeter is used to read only a fraction of the voltage of the standard-under-test which reduces the contribution of the DVM uncertainty to the overall measurement uncertainty. When comparing the standard-under-test to the Transfer Reference (with voltage taps at $1.018 \mathrm{~V}$ increments) the maximum reading required of the DVM is $0.509 \mathrm{~V}$. Thus,

$$
U=\frac{V_{\mathrm{Z}}-(N) 1.018}{V_{\mathrm{Z}}} U_{\mathrm{DVM}}
$$

where $U_{D V M}$ is the DVM uncertainty expressed as a percentage of reading, $V_{\mathrm{Z}}$ is the voltage of the solid-state standard, $N$ is the number of resistors, and $U$ is the final DVM uncertainty as a percentage of $V_{Z}$. For a worst case of $V_{\mathrm{Z}}=5.6 \mathrm{~V}, U=0.09 U_{\mathrm{DVM}}$, and for $V_{\mathrm{Z}}=10 \mathrm{~V}, U=0.02 U_{\mathrm{DVM}}$. Therefore, if the DVM can be calibrated to an accuracy of $1 \mathrm{ppm}$ the worst case error contribution is $0.09 \mathrm{ppm}$. 
The linearity of the DVM is checked as necessary, but the gain of the one volt range of the DVM is calibrated every time measurements are made by measuring the $1.018 \mathrm{~V}$ developed across two of the resistors in the Transfer Reference; typically resistors $R_{1}$ and $R_{2}$ are used (see Fig. 2.). This is done to evaluate the effect of measuring voltages at ground and above ground. Gain calibrations from several days can be combined to detect a systematic bias in the measurements with respect to the particular resistor used. Such measurement errors can be caused by excessive DVM leakage or bias currents and will also affect the accuracy of the comparisons between the Transfer Reference and the standard cell reference group.

Once the Transfer Reference has been calibrated in terms of the reference standard cells the linearity of the DVM on the $10 \mathrm{~V}$ range can be checked by directly measuring the ten voltages, 1.018 to $10.18 \mathrm{~V}$, developed across the resistors. Although not a thorough calibration of the DVM linearity, this test can be used to detect significant changes in the linearity errors.

The DVM is used on the $0.1-V$ range to improve the resolution of comparisons of $1.018-\mathrm{V}$ solid-state standards to the Transfer Reference, and of the comparisons of the Transfer Reference to the reference standard cells. The gain error of the $0.1-\mathrm{V}$ range is not calibrated daily by the system but, the largest expected measurement difference for these comparisons is only $200 \mu \mathrm{V}$. Thus for an overall measurement error of $0.005 \mathrm{ppm}$ (of $1.018 \mathrm{~V}$ ) the gain need only be known to $250 \mathrm{ppm}$. The gain of the $0.1-\mathrm{V}$ range is periodically checked using external standards to ensure that it is within this limit.

The final value for each solid-state standard under test is computed by correcting the measured difference between the standard and the Transfer Reference for the gain of the DVM, and adding this to the value of the appropriate tap of the Transfer Reference. The calibrated values of the Transfer Reference are determined using a least-squares analysis of the redundant measurements that compared the 10 outputs of the Reference to the reference standard cell group. The mean of the "before" and "after" calibrations is used.

\section{Operational Procedures}

\section{Client Standards Handling}

Standards shipped to NBS under power are hand carried from the Building 301 Receiving Room as soon as Electricity Division personnel are notified. The temperature is checked by qualified laboratory staff (if the standard has a temperature measuring device) and the standard is brought to the Volt Facility Laboratory. All solid-state standards to be calibrated are connected to the measuring system scanner at the time of their arrival and are left undisturbed until the test is completed. When the standard is received it is 
assigned a unique ID number, usually a subset of the serial number, and this is entered into a log book along with the date and the condition of the standard. Measurements are begun the day after the arrival of the unit. After the test is completed, the client is notified and the standard is repacked in its original shipping material and returned to the client.

\section{Daily Procedures}

\section{Calibration of Working Group C}

Working Group $\mathrm{C}$ is used as the reference for all solid-state measurements in the Volt Facility Laboratory. Working Group C is compared daily to two groups of primary cells (Primary Groups A and B) using the automated standard cell comparison system VTP [1]. These measurements are made early in the morning before measurements of solid-state standards are begun and the data is immediately reduced to determine the values of the cell emfs of Working Group C. These values are used for the solid-state standard measurements done that day.

\section{Calibration of Solid-State Standards}

The operator must set up a measurement procedure file (RUNFILE) that has a list of all the standards to be calibrated. Program EDITA, a general purpose text editor, is usually used to modify the previous day's file. The exact format of the file is described in Appendix B, but in general the file contains the measurement sequence for calibrating the Transfer Reference, a list of identification numbers of the standards-under-test, their scanner circuit numbers, and the approximate voltage of each of the standards. The operator manually measures the temperature of Working Group C before the measurements are begun and enters this into the file along with the cell emf values (from the comparisons with the primary groups). When the file is complete the measurement program (READZEN) is started and measurements proceed automatically with the fully corrected values of the solid-state standards printed out and saved on disk at the conclusion of the measurements.

READZEN first checks the measurement system apparatus to make sure everything is functionally working. This includes sending a clear-allchannels command to the scanner and checking to see if it responds, sending an initialization command to the DVM and checking it's response, checking that the manual front/rear input switch on the DVM is set properly, checking to see if the hard disk/file server is connected and turned on (if it is to be used), checking that the printer is turned on and loaded with paper, and finally, checking that a properly initialized data disk and a program disk containing a RUNFILE are in their respective disk drives. Multiple RUNFILEs may be included on the program disk for different sets of measurements; the operator selects the desired one at the time the program READZEN is run. 
Measurements are started by setting the DVM to the $0.1-\mathrm{V}$ range and shorting the DVM input to discharge the input capacitance. Then the ten 1.018-V outputs of the Transfer Reference are compared to the Working Group $\mathrm{C}$ cell emfs using the redundant measurement design discussed in section 3. Forty measurements are required and the data is saved on disk; this process takes about $1 / 2$ hour. Measurements of the unknown solidstate standards are preceded by gain calibrations of the DVM $1-V$ range. DVM gain calibrations consist of directly measuring (in both forward and reverse polarity) two of the Transfer Reference voltages (1.018 V) using the 1-V range of the DVM as discussed above.

The solid-state standard voltages are measured by comparing each one in turn to the tap on the Transfer Reference that is closest in voltage to the standard's voltage and measuring the difference with the DVM set on the $1-\mathrm{V}$ range (in both forward and reverse polarity). Once all the unknown standards have been measured the measurement sequence repeats starting with the DVM calibrations. This measurement sequence (including the DVM calibrations) is repeated three times and then a final (fourth) DVM calibration is done. At the conclusion of these measurements, the Transfer Reference is recalibrated against Working Group C. To summarize, the measurement sequence is - calibrate the Transfer Reference using Group C, calibrate the DVM, measure the unknown standards, calibrate the DVM, measure the unknown standards, calibrate the DVM, measure the unknown standards, calibrate the DVM, and finally calibrate the Transfer Reference a second time.

\section{Analysis of the Daily Data}

At the conclusion of all the measurements for the day, the READZEN program automatically calculates the emfs of the standards-under-test and produces a two page printout summarizing the calibration of the Transfer Reference and listing the emfs of the solid-state standards. The emfs of the standards (as well as intermediate results) are also saved on two disk files, one on a floppy disk, and the other on the hard disk. These data are combined with other daily data sets for assigning the final emf values to the standard.

Figures $3 \mathrm{a}$ and $3 \mathrm{~b}$ are copies of the two pages of a typical daily printout produced by READZEN. At the top of page 1, below the date and the name of the RUNFILE that was used, is a summary of the measurements made, and their starting time. In the example shown the Transfer Reference (denoted Transfer Zener in Fig. 3a) was compared to Working Group C (2800) at 8:03 and 10:07 am. The unknown solid-state standards were compared to the Transfer Reference three times: 8:35, 9:05, and 9:35 am. This part of the log is printed as the measurements are being taken so the operator can track the operation of the program. 


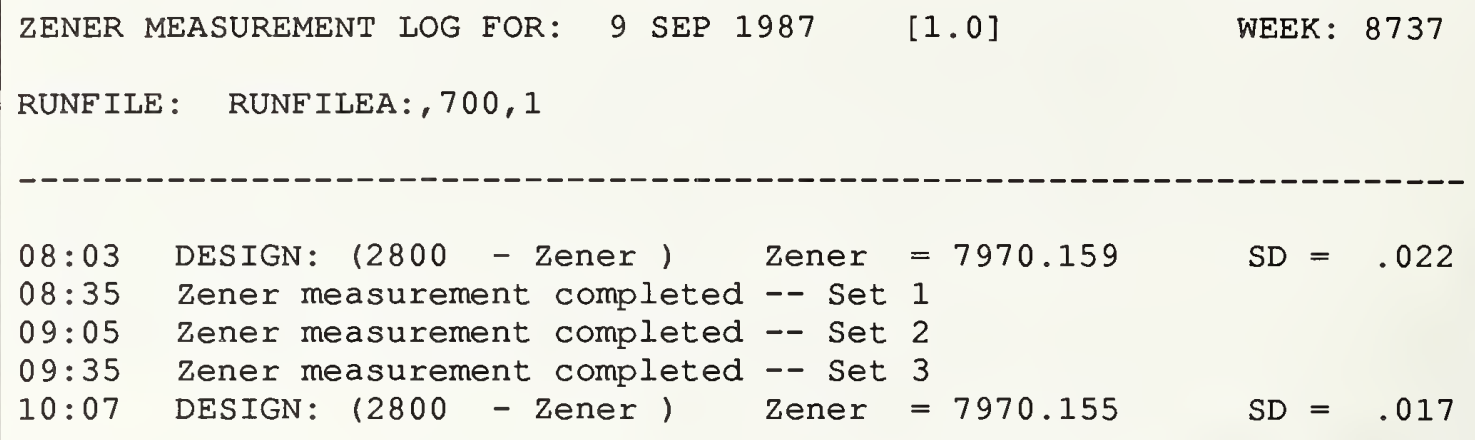
.022
.008
.017
.006
30.0135
30.0135
Standard Deviations (uV)
Reference Cell Box Temps (C)
Reference
Cells

Res

Value at

$08: 03: 56$

$\begin{array}{ll}2801 & 1 \\ 2802 & 1 \\ 2803 & 1 \\ 2804 & 1\end{array}$

Mean

8166.558
8164.409
8165.602
8166.147
8165.679

$<.003>$

$<-0.000>$

$<.007>$

$<-0.010>$

$<0.000>$

Transfer Zener

$\begin{array}{lllll}\mathrm{Z} 1 & 7978.379 & <0.000> & 7978.380 & 7978.379 \\ \mathrm{Z} 2 & 7976.446 & <-.021> & 7976.425 & 7976.436 \\ \mathrm{Z} 3 & 7932.627 & <-.006> & 7932.621 & 7932.624 \\ \mathrm{Z} 4 & 7956.967 & <-.004> & 7956.963 & 7956.965 \\ \mathrm{Z} 5 & 8052.081 & <-.011> & 8052.071 & 8052.076 \\ \mathrm{Z} 6 & 7954.107 & <-.015> & 7954.092 & 7954.099 \\ \mathrm{Z} 7 & 7956.854 & <-.006> & 7956.848 & 7956.851 \\ \mathrm{Z} 8 & 7966.002 & <-.006> & 7965.996 & 7965.999 \\ \mathrm{Z} 9 & 7958.452 & <-.019> & 7958.471 & 7958.461 \\ \mathrm{Z} 10 & 7969.671 & <-.015> & 7969.686 & 7969.678 \\ \text { Mean } & 7969.671 & <-.004> & 7970.155 & 7970.157\end{array}$

DVM CALIBRATION SUMMARY

Number of DVM calibrations = Mean DVM error (ppm) = 8
2.0
.1

std. Dev. of mean error $=\quad .1$

Fig. 3a. Page 1 of a typical daily printout from the measurement program READZEN. 
page 2

ZENER CALIBRATION SUMMARY FOR: 9 SEP 1987

\begin{tabular}{|c|c|c|}
\hline Zener ID & $\begin{array}{l}\text { Voltage } \\
\text { (volts) }\end{array}$ & $\begin{array}{l}\text { Std. Dev } \\
\text { (ppm) }\end{array}$ \\
\hline $188 / 1$ & 9.99999654 & .145 \\
\hline $188 / 2$ & 1.01813796 & .220 \\
\hline C5950/1 & 9.99999937 & .006 \\
\hline $\mathrm{C} 6015 / 1$ & 10.00000245 & .002 \\
\hline $5027 / 1$ & 10.00002831 & .004 \\
\hline $5027 / 2$ & 1.01799749 & .011 \\
\hline $5027 / 3$ & .99999292 & 0.000 \\
\hline $5010 \mathrm{~N} / 1$ & 10.00003443 & 0.000 \\
\hline $5010 \mathrm{~N} / 2$ & 1.01800020 & .008 \\
\hline $5010 \mathrm{~N} / 3$ & 1.00000492 & 0.000 \\
\hline $5011 / 1$ & 10.00002566 & .031 \\
\hline $5011 / 2$ & 1.01799755 & .028 \\
\hline $5011 / 3$ & 1.00000773 & .036 \\
\hline $5018 / 1$ & 9.99999464 & .004 \\
\hline $5018 / 2$ & 1.01799740 & .007 \\
\hline $5018 / 3$ & .99997592 & 0.000 \\
\hline $\mathrm{BFE} 1 / 1$ & 1.01899358 & .020 \\
\hline $49105 / 1$ & 9.99987041 & .026 \\
\hline $49105 / 2$ & 1.01798278 & .010 \\
\hline $49105 / 3$ & .99998092 & 0.000 \\
\hline $49105 / 4$ & 6.99989104 & .052 \\
\hline $49111 / 1$ & 9.99990381 & .027 \\
\hline $49111 / 2$ & 1.01798826 & .017 \\
\hline $49111 / 32$ & .99998952 & .042 \\
\hline $49111 / 4$ & 6.99992458 & .047 \\
\hline $5035 / 1$ & 10.00000727 & .014 \\
\hline $5035 / 2$ & 1.01799416 & .013 \\
\hline $5035 / 3$ & .99999792 & 0.000 \\
\hline
\end{tabular}

ALL CALCULATIONS COMPLETED AND SRM UPDATED

Fig. 3b. Page 2 of a typical daily printout from the measurement program READZEN. 
The comparisons of the Transfer Reference to 2800 (Working Group C) are summarized under the heading REFERENCE CELL STATISTICS. The standard deviations are the standard deviations of a single observation from the redundant measurement design [3]. The emfs of the reference cells in 2800 and the 1.018-V outputs of the Transfer Reference (labelled Z1 to Z10) are expressed in microvolts reduced by 1.01 volts. The mean values from the two calibrations are used as the values of the Transfer Reference for calculating the values of the solid-state standards under test. The emf differences between two calibrations are calculated and printed in the Difference column to aid the operator in detecting abnormal changes.

At the bottom of Fig. 3a a short summary of the DVM calibrations appears. In this example the DVM was compared to two different resistors before and after each set of Zener measurements ([3 sets +1$] \times 2$ ) for a total of 8 calibrations. The mean DVM error on the $1-\mathrm{V}$ range was found to be $(2.0 \pm 0.1)$ ppm.

Fig. $3 b$, page 2 of the printout, lists the standards under test, their average measured voltage, and the standard deviation of the measured voltage as determined from the repeated sets of measurements ( 3 in this case). The repeated measurements are performed over a relatively short period of time ( 1 to 2 hours) to reduce the variability of the final averaged values. The complete set of measurements described above is considered to be a single measurement of each standard consisting of the one averaged value for that standard.

\section{Assignment of the Final Value}

Client standards are measured in terms of NBS working cells once a day (using the above procedure) for at least ten working days. The measured values are plotted and the data are reviewed by laboratory staff to determine if the outputs exhibit sufficient stability for a report to be issued. If so, the mean of the all the daily measurements is used as the final assigned value for the output of the standard. In some rare cases standards have shown an initial drift for the first few days after arriving at NBS. If this happens additional measurements are taken so that at least ten stable measurements are obtained, and the early unstable readings are not used in determining the final value. Even if the standard behaves properly, the exact number of measurements used for any calibration is not fixed; it depends on when the standard was received, when the client requires that it be returned, etc., but at least ten measurements are always used and usually not more than fifteen.

Figure 4 shows the measured values of three outputs of a typical Zener standard. The outputs are all derived from the same Zener reference device; the $1.018-\mathrm{V}$ and $1-\mathrm{V}$ outputs are obtained from internal resistance dividers connected to the $10-\mathrm{V}$ output. 


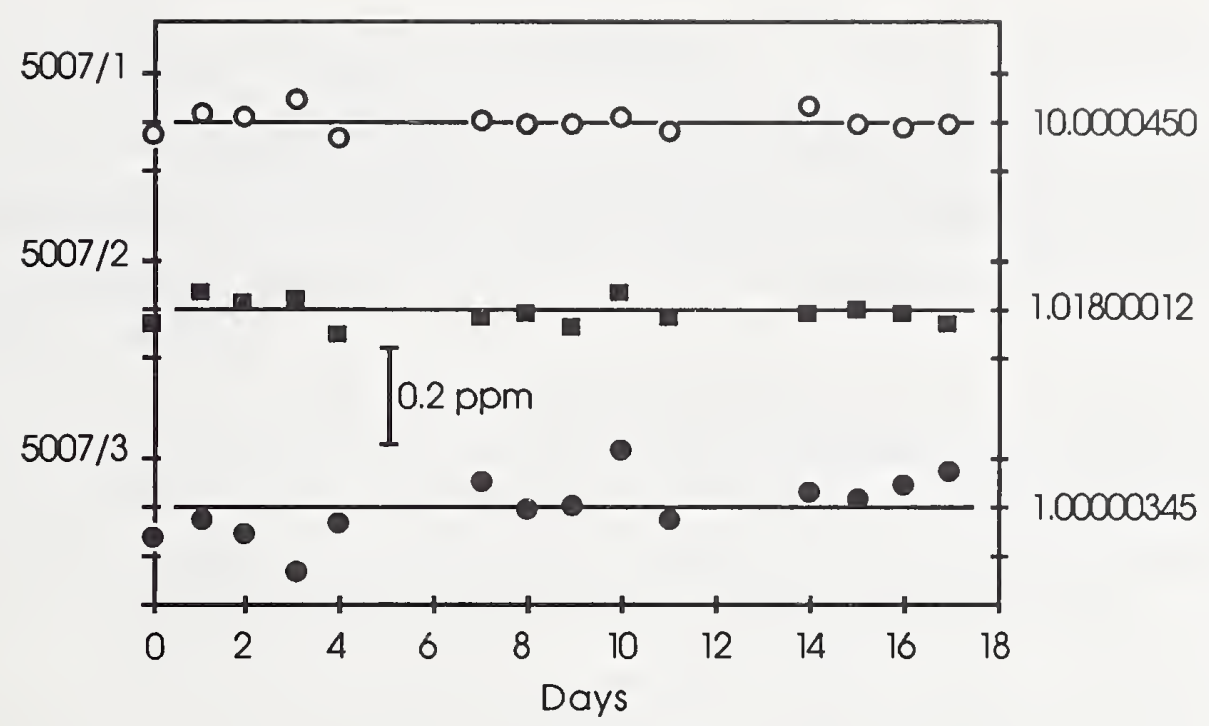

Fig. 4. The three voltage outputs of a typical solid-state standard sent to NBS for calibration. The outputs are plotted in ppm from their mean voltage. The solid line is drawn at the mean value which is also labelled (in volts) on the right axis.

\section{Uncertainty}

The measuring system was designed principally to measure solid-state standards in the range $5-10 \mathrm{~V}$. Table I lists the sources of uncertainty in the measuring system extrapolated to the worst case unknown voltage in the $5-10 \mathrm{~V}$ range. The system may be used over the $1-5 \mathrm{~V}$ range but with somewhat reduced accuracy when the unknown voltage is not near a cardinal value $(1.018,2.036,3.054, \ldots \mathrm{V})$.

\section{Explanation of Table Items}

By far the most critical component of the system is the digital voltmeter. The DVM gain is measured during the course of the Zener measurements and the gain error of the $1-\mathrm{V}$ range is calculated and applied as a correction to the DVM readings. An allowance is included in the Table for the inaccuracy of this gain measurement.

The DVM linearity was initially checked on the $10-\mathrm{V}$ range using a calibrated, manual 7-dial Kelvin-Varley divider, and measurements on similar DVMs indicate little or no change in the linearity with time. The linearity error is typically a maximum of $0.7 \mathrm{ppm}$ or less at half-scale input and no correction to the data is made for it. Provision has been made for the system to calibrate automatically the linearity of the DVM at 10 points on the $10-\mathrm{V}$ range by measuring the 10 voltages $1.018,2.036, \ldots, 10.18 \mathrm{~V}$ although this is not done routinely. 
Source of Uncertainty

DVM gain uncertainty

DVM linearity uncertainty

DVM leakage/bias currents

Standard cell leakage currents

Scanner switch thermal emfs

Random uncertainty in calibrating the Transfer Reference

Random uncertainty in calibrating the client standard (within-day)

RSS subtotal

Uncertainty in value of Working Group C

Change in Working Group C during the day

Uncertainty of the value assigned to the client standard
1 std. dev. estimate (ppm)

0.020

0.062

0.023

0.006

0.013

0.007

0.013

0.072

0.040

0.047

RSS Total

0.095

The DVM leakage and bias currents and standard cell leakage currents were measured directly with an electrometer and their effects on the measurement calculated.

The crossbar scanner switch thermal emfs were measured with the DVM by shorting the input leads and measuring the residual voltages.

The random uncertainties in calibrating the Transfer Reference and the client standards are estimated from the pooled standard deviations of the measurement designs. Although these uncertainties tend to be reduced by averaging ten measurements of the client standard we prefer to include them for completeness. 
Two sets of DVM readings are taken for every voltage measurement (both for standard cells and solid-state standards), one with the input voltage source connected normally and a second with the voltage source polarity reversed by the crossbar scanner. Subtracting the second reading from the first and dividing by two yields a measurement free from any error due to a non-zero DVM offset, thus no allowance has been included in the Table for DVM offset errors.

Ac effects observed in an earlier system were found to be negligible in this system [2]. The ac effects on the Zener reference of the Transfer Reference were estimated by monitoring changes in its voltage using a passive measurement circuit referenced to a standard cell while ac was introduced into the system by connecting the DVM to the Transfer Reference taps.

The RSS subtotal represents the ratio error in comparing an arbitrary voltage source to a group of $1.018-\mathrm{V}$ standard cells. For establishing an uncertainty for the client standards with respect to the U.S. Legal Volt, the uncertainty of Working Group $\mathrm{C}$ must be added. The uncertainty of the value of Working Group C computed from earlier measurements is developed in reference 1 and will not be repeated here. An additional uncertainty is included, however, for temperature instabilities and other related emf variations in the present standard cell enclosure used for Working Group $\mathrm{C}$ that cause the cell emfs to change during the day.

As far as is known, all systematic errors listed in Table I are independent of each other. Therefore, they are combined in root-sum-square (RSS) fashion along with the random errors. The final reported uncertainty for a client standard ( $U_{\text {reported }}$ ) is three times the root-sum-square of the above measurement uncertainty and the standard deviation of the mean of the ten daily measurements $\left(\mathrm{s}_{\mathrm{m}}\right)$, i.e.,

$$
\mathrm{U}_{\text {reported }}=3\left[\sqrt{\left(0.095^{2}+\mathrm{s}_{\mathrm{m}}^{2}\right)}\right] .
$$

\section{Quality Control Procedures}

\section{Measurement System Verification}

As discussed in Section 5 all major sources of error in the measuring system are evaluated during the measurements and corrections are applied to the data as necessary. The printout from READZEN is reviewed daily by laboratory personnel to verify that all the measurements are in statistical control. 
Other potential sources of error include uncompensated thermal emfs in the crossbar switches and in the leads to the standards and circulating ground currents within the measuring instrument and between the measuring instrument and the client standard. Several quality control procedures are periodically performed to estimate or eliminate these uncertainties.

Thermal emfs in the leads from the standards to the crossbar switch are evaluated regularly. The positive and negative leads are shorted together at the end where they would normally connect to the standard and a redundant measurement design is done between the two sets of shorted leads using the DVM as the detector. These thermal emf measurements are performed as standards leave the laboratory and leads become free. Experience has shown that the thermal emfs are usually small and fairly constant (approximately $15 \mathrm{nV}$ or less).

Leakage resistance and leakage current measurements are made periodically between the different parts of the measuring system using an electrometer to ensure that they are at acceptable levels.

A $10-\mathrm{V}$ standard that is not moved is measured every day as part of the workload and serves as a check standard to monitor the long term stability of the measurement system. The $10-\mathrm{V}$ output of the standard is plotted versus time in Fig. 5.

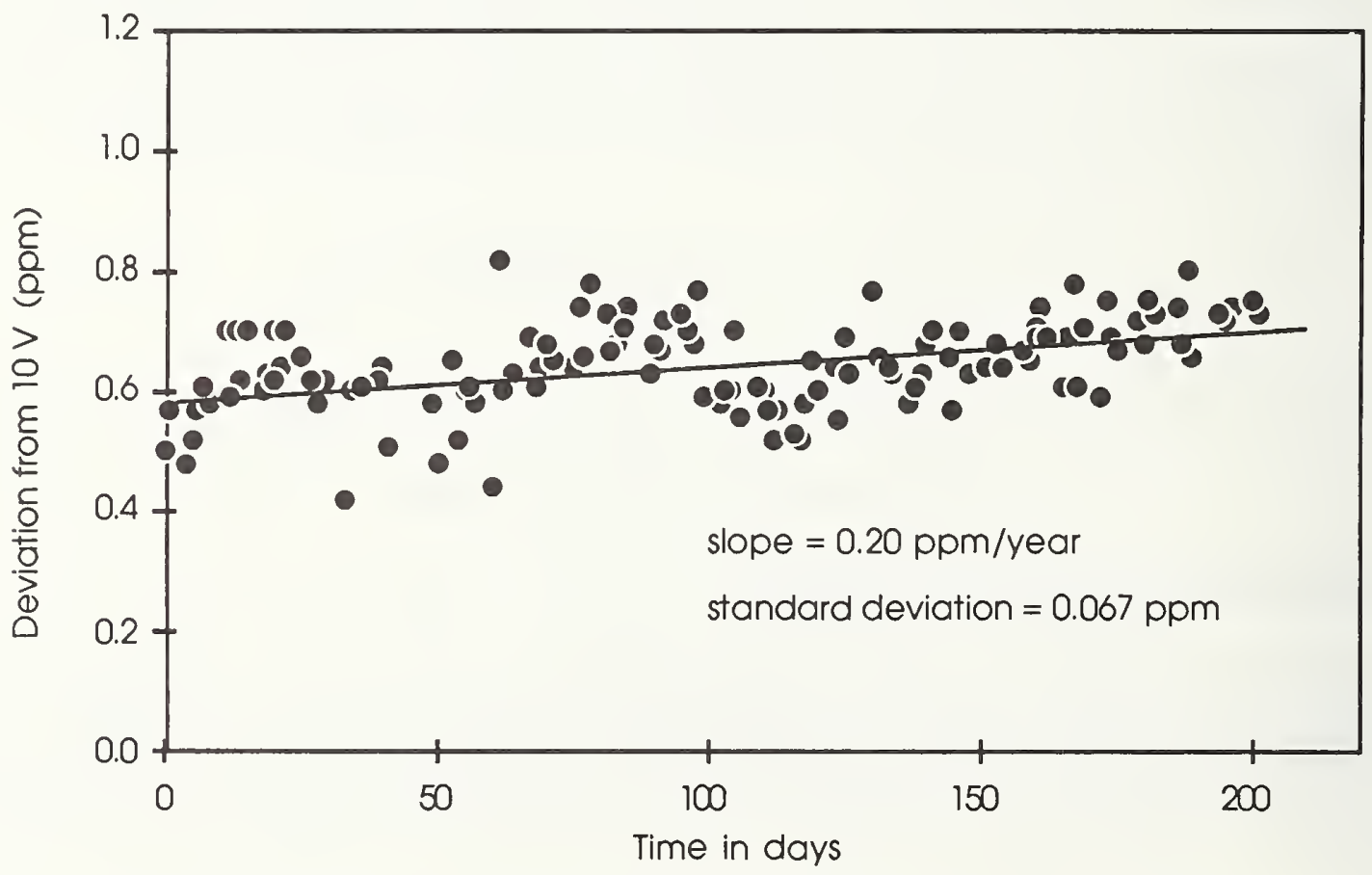

Fig. 5. Ten volt output of a check standard as measured by the system. 


\section{Client Standard Evaluation}

Tests for ac effects are done for each new type of standard received for test. Some models of standards produce a dc shift of the output voltage when an ac source is connected to the output terminals. Experiments have shown that for some standards the DVM can produce a significant shift [2]. These experiments also showed that the effect was model dependent, not standard dependent; all items of a particular model tested either had the problem or they did not. Any new, unfamiliar model received is tested for ac effects by applying a small ac signal to the output while observing the dc voltage. 


\section{Bibliography}

1. Field, B. F., "NBS Measurement Services: Standard Cell Calibrations," Natl. Bur. Stand. (U.S.), Special Publ. 250-24, 52 pages (1987).

2. Field, B. F., "A Sub-PPM automated 1-10 Volt DC Measuring System," IEEE Trans. Instrum. Meas., Vol. IM-34, No. 2, pp. 327-330 (1985).

3. Eicke, W. G. and Cameron, J. M., "Designs for Intercomparing Small Groups of Saturated Standard Cells," Natl. Bur. Stand. (U.S.), Tech. Note 430, 19 pages (1967).

4. Eicke, W. G., "Comments on Zener diodes as voltage standards," Comité International des Poids et Mesures, Comité Consultatif d'Electricité, 10th Session, p. 27 (1963).

5. Eicke, W. G., "Making precision voltage measurement on Zener diodes," IEEE Trans., Paper CP 63-416 (1963).

6. Eicke, W. G., "The Operating Characteristics of Zener Reference Diodes and their Measurement," ISA Transactions, Vol. 3, No. 2, pp. 93-99 (1964).

7. Huntley, L., "The Fluke direct voltage maintenance program," Proc. 1984 Meas. Sci. Conf., pp. 147-151 (1984).

8. Koep, K. J., "The use of a solid state dc voltage transport standard to transfer the dc volt in a regional standard cell MAP program," Proc. 1984 Meas. Sci. Conf., pp. 142-146 (1984).

9. Murray, W. and Dencher, P., "High-accuracy voltage transfer using a modified commercial solid-state reference," J. Phys. E.: Sci. Instrum., Vol. 17, No. 5, pp. 354-356 (1984).

10. Spreadbury, P. J. and Everhart, T. E., "Ultra-stable portable voltage sources," IEE Conf. Publ., Vol. 174, pp. 117-120. 


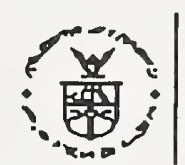

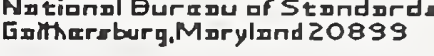 \\ REPORT OF CALIBRATION

\author{
Solid-State Voltage Standard \\ XXXXX Model YYYY DC Reference Standard \\ Serial No. 1111111 \\ Submitted by \\ $\mathrm{xxXXXXXX}$

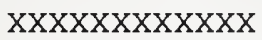

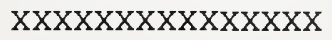

UNITED STATESDEPARTMENT OF COMMERCE

This voltage standard was calibrated during the period June 1 , 1987 to June 18, 1987, by comparing its output voltages with those from a calibrated ten step divider driven by a stable ten volt source. The difference voltages were measured using a calibrated digital voltmeter. This measuring system was standardized by saturated standard cells calibrated in terms of the U.S. Legal Volt (volts-NBS) using standard NBS procedures. The solid-state voltage standard was received with the IN CAL light on and with a thermistor resistance of 3.91 kilohms. The unit was plugged into the ac power line for all measurements.

The values given in the table below are the mean values of the results of the individual calibrations summarized in the Appendix. The uncertainties given are three standard deviation estimates equal to three times the root-sum-square of the estimated $0.095 \mathrm{ppm}$ one standard deviation uncertainty in the measurement system (primarily systematic or type B), and the one standard deviation random (type A) uncertainty of the mean of the measurements on the individual voltage standard output.*

Nominal Output Measured Voltage Uncertainty Uncertainty (volts-NBS) (ppm) (microvolts)
10 volts
10.0000450
0.29
2.86
1.018 volts
1.0180001
0.29
0.29

* The nomenclature 'type $A$ ' and 'type $B$ ' and the procedure used to combine them to obtain the total uncertainty has been recommended by the International Bureau of Weights and Measures

(BIPM) Working Group on the Statement of Uncertainties, see Metrologia, vol. 17, No. 2, p. 73 (1981).

Test No. $521 / \mathrm{XXXXXXXXX}$ 
Solid-State Voltage Standard

XXXXX Model YYYY DC Reference Standard

Serial No. 1111111

These uncertainty figures contain no allowance for the effects of transport of the standard back to the user. Any valid uncertainty statement applying to the above values when the standard is used other than in this laboratory must contain an additional uncertainty component. Also not included in the above uncertainties is an allowance for long term drift of the output voltages of this standard. This must be determined from historical data on a case by case basis.

For the Director

National Measurement Laboratory

Norman B. Belecki, Physicist

Electricity Division

Center for Basic Standards

Test No.: 521/XXXXXXXXX

Reference: XXXXXXXXXXXX

Date: September 8, 1987 
Solid-State Voltage Standard

XXXXX Model YYYY DC Reference Standard

Serial No. 1111111

\begin{tabular}{|c|c|c|c|}
\hline \multirow{2}{*}{\multicolumn{4}{|c|}{$\begin{array}{c}\text { APPENDIX } \\
\text { (values in volts }\end{array}$}} \\
\hline & & & \\
\hline Date & Time & 10 volts & 1.018 volts \\
\hline $06 / 01 / 87$ & $10: 19$ & 10.0000448 & 1.0180001 \\
\hline $06 / 02 / 87$ & $10: 58$ & 10.0000452 & 1.0180002 \\
\hline $06 / 03 / 87$ & $09: 52$ & 10.0000451 & 1.0180001 \\
\hline $06 / 04 / 87$ & $12: 16$ & 10.0000454 & 1.0180001 \\
\hline $06 / 05 / 87$ & $10: 07$ & 10.0000447 & 1.0180001 \\
\hline $06 / 08 / 87$ & $10: 27$ & 10.0000450 & 1.0180001 \\
\hline $06 / 09 / 87$ & $09: 12$ & 10.0000450 & 1.0180001 \\
\hline $06 / 10 / 87$ & $09: 34$ & 10.0000450 & 1.0180001 \\
\hline $06 / 11 / 87$ & $09: 33$ & $1 C .0000451$ & 1.0180002 \\
\hline $06 / 12 / 87$ & $11: 20$ & 10.0000448 & 1.0180001 \\
\hline $06 / 15 / 87$ & $11: 03$ & 10.0000453 & 1.0180001 \\
\hline $06 / 16 / 87$ & $11: 03$ & 10.0000449 & 1.0180001 \\
\hline $06 / 17 / 87$ & $09: 39$ & 10.0000448 & 1.0180001 \\
\hline $06 / 18 / 87$ & $09: 38$ & 10.0000450 & 1.0180001 \\
\hline Mean (volt & $-\mathrm{NBS})$ & 10.0000450 & 1.0180001 \\
\hline \multicolumn{4}{|c|}{ Standard Deviation } \\
\hline Number of & ead & 14 & 14 \\
\hline
\end{tabular}

Test No.: $521 / \mathrm{XXXXXXXXX}$

Reference: $\mathrm{XXXXXXXXXXXX}$

Date: September 8, 1987 


\section{Appendix B - Measurement Software}

The READZEN program is a generalized measurement program that runs under the direction of an ASCII text file (RUNFILE) and is used to make all the measurements required for solid-state standard calibrations. Program EDITA is a general purpose editor program for creating and modifying RUNFILEs. The following sections describe how to operate the programs and the purpose of some of the important program variables. It is assumed that the reader is familiar with the BASIC language environment (Rocky Mountain BASIC) used with the Hewlett/Packard model 200/300 desktop computers.*

\section{Program READZEN}

READZEN is the main measurement and calculation program. It has the capability of doing standard cell intercomparisons, least-squares cell data reduction, Zener-Transfer Reference comparisons, and Zener data reduction. The operation of the program is controlled by an ASCII text file named RUNFILExxx that is stored on the program disk. The xxx indicates a 1 to 3 character suffix of numbers or letters. The suffix is used to differentiate between several Runfiles that may be stored on the same disk but were created for different measurement procedures, i.e., normal workload measurements, special tests, etc. At runtime the operator is prompted to select one.

At the beginning of the program code of READZEN are comments on the purpose of the program, array variable dimension statements, and a number of variables that define the various defaults of the program. These variables control things like the specification of the program disk and data disk storage units, the 488 bus addresses of the measuring system instruments, and other internal variables used to control calculations and data storage. These variables are described in detail below. Program operations that may be optionally changed by the user are generally controlled by these variables. No modification to the program code itself should be necessary.

\section{Running the program}

When the program is started an informational screen is shown giving the name, version number, and purpose of the program, and all the scanner channels are opened. If the scanner is not connected or turned on a message is printed and the program is stopped. Similarly, the printer is checked and the disk drives are checked for the program and data disks. If

\footnotetext{
Specific model names are used for clarification only and their use does not constitute an endorsement by NBS as the best available equipment. Other instruments may be as suitable, or more suitable, for the applications described.
} 
all is in order, the Runfile names on the program disk are displayed along with an ID number, a 20 character identifying line, and the creation date of the file. The operator must enter the ID number of one of the Runfiles. Once this has been done the measurements proceed automatically with no further operator control. At the conclusion of the measurements the results are printed on the printer and saved on disk.

\section{Program options}

Variables to control the data storage and bus addresses of the measuring instruments are contained in lines 1270 to 1641 of READZEN. A description of some useful variables follows with their normal values shown in parentheses.

Observer\$ is an identifying name for the system.

(Observer\$="Micky")

Zsets

is a counter for the number of times the Zener references are compared to the transfer reference. Under special circumstances more or fewer measurements may be desired. (Zsets=3)

Dvmcorr is a "gain" value that is used to multiply all DVM readings taken on the $0.1 \mathrm{~V}$ scale. If the $0.1 \mathrm{~V}$ scale is known to have a significant gain error this variable can be set to compensate for it; e.g., if the gain error is $-100 \mathrm{ppm}$, the DVM reading is lower than the actual value, set Dvmcorr $=1.00010$. Generally, the DVM is physically adjusted if the gain is significantly in error.

(Dvmcorr $=1$ )

$\mathrm{Dk} \$$

Progdk\$

Srm\$

Dir\$ is the data disk specifier. (Dk\$=":,700,0")

is the program disk specifier.

(Progdk\$=":,700,1")

is the suffix for the SRM.

(Srm\$=":REMOTE")

is a prefix directory name for the SRM. This name will preface the data file name, and $\operatorname{Srm} \$$ will be appended to the end to form a complete filename.

(Dir\$="ZENDATA/") 
Zener_volt $\$$ is the partial filename for result files. Calculated standard cell results preface Zener_volt\$ with a "D" and Zener reference results preface it with an "R". For both, the 2 digit year and a 2 digit week number within the year are appended to the filename. Zener_volt $\$$ should be 4 characters or less, otherwise the filename will be too long.

(Zener_volt\$="ZEN")

Hcopy

controls the printing of measurement data, intermediate results, and final results to the printer. If $\mathrm{Hcopy}=0$ (normal default) one line is printed on the printer each time a measurement set (cells or Zeners) is completed. The printer output becomes a log of the measurements; the actual measurements are not printed. The results of the cell calculations and the final Zener results are also printed. If Hcopy $=1$ then log printing is suppressed but cell and Zener results are printed. If Hcopy $=2$ all the measurement data (cell-pair differences and Zener differences) are printed to the printer as well as the results. If Hcopy $=-1$ nothing is printed to the printer. (Hcopy $=$ 0 )

Srm

controls whether data is saved on an SRM in addition to the floppy disks. It should be set to either Yes or No. If Yes, check to make sure that Dir\$ is correctly set to the subdirectory desired. (Srm=Yes)

Saveflag

controls saving of data on floppy disk and the SRM. For Saveflag set equal to 1, all measurement data files and result files are saved on disk. To save space on disk Saveflag may be set equal to 0 so only the cell and Zener result files are saved. If Saveflag $=-1$ only the final Zener result files are saved. $($ Saveflag $=1)$

File use

READZEN automatically creates as needed a number of data files. These are all ASCII files with data stored as strings. Each line in the file is stored as one string and may contain an arbitrary number of items with the items 
separated by at least one space. All files are read using a free-field format; only the order of the data is important, not the position on any one line. File names are generally composed of a unique prefix identifying the type of file and a suffix based on the date. The date suffix is either of the form YYMMDD or YYWW where YY is the year, MM is the month, DD is the day, and WW is the number of the week in the year. WW starts with 1 for the first week of the year and automatically changes on Sunday for the next week. The exact style of the date suffix depends on whether the file contains one day's data or one week's. The exact format of the data stored in the files is discussed below.

The creation and use of the files is as follows: Intercomparisons between the reference standard cells and the Transfer Reference produce 40 voltage difference readings ( 4 cells by 10 resistors). These difference readings are stored in an "S" file, i.e., SYYMMDD. All intercomparisons performed in one day are stored one after the other in the file. READZEN performs a least-squares calculation on the "S" data and saves the calculated cell values and "resistor-voltages" from the Transfer Reference in a "D" file, i.e., DZEN_YYWW. All standard cell and Transfer Reference voltages for the entire week are stored in this file. The raw difference readings between the Zener standards under test and the Transfer Reference are stored in "Z" files, i.e., ZYYMMDD. After calculation the final Zener values are stored in "R" files, i.e., RZEN_YYWW.

The files are initially created with a specified size and once created cannot be increased beyond this size. They have generally been made large enough to handle one or two sets of measurements per day. If the file size is consistently too small the initial size specification may be increased. "S" files are created in line 4780 of READZEN and are specified as 68 records of 256 characters/record. "D" files are created in line 11840 and are specified with a length of 20 records of 256 characters/record. "Z" files are created in line 8100 with a length of 20 records of 256 characters/record. "R" files are created in line 12980 with a length of 20 records of 256 characters/record.

\section{Program EDITA}

EDITA is a general purpose ASCII text file editor for viewing, printing, and modifying the input and output files generated by READZEN. Prior to running READZEN a RUNFILE is created using EDITA which details the measurements to be made for that day. The specific RUNFILE format is described in the next section on file formats.

Running the program.

When the program is started it asks for a file storage device. This is the floppy disk or hard disk on which a previously created file is stored or a new file is to be stored. Enter a standard H/P disk designator without any quotes, e.g., :,700,0. The program then prompts for a file name; enter the 
name of an existing file or a name for the new file to be created. If the program cannot find the file on the specified disk, it will ask if a new one should be created. Enter $\mathrm{Y}$ or $\mathrm{N}$ as appropriate.

Most operations are controlled by the function keys at the top of the keyboard. They are:

fl PREV SCREEN Scroll up to display the previous screen of data.

f2 NEXT SCREEN Scroll down to display the next screen of data.

f3 FIND CHRS

Find a string of characters within the text.

f4 2ND KEY LEVEL Change the key functions to the alternate (2nd) set.

f5 APPEND ON (OFF) With append on additional lines may be added to the file, with append off the original length is preserved.

f6 GO TO LINE Go to the specified line number.

f7 MOVE/DEL COPY Move, delete, or copy a block of lines.

f8 END PROGRAM Stop the program without saving the file.

2nd Key Level

fl STORE TEXT Save the file in the previously specified name.

22 MERGE FILES Append another file to the end of the existing one in memory.

f3 NEW STORAGE Specify a new disk designator

f4 1ST KEY LEVEL Return to the original key functions

f5 NEW PRINTER Specify the printer select code (usually 701). Note: this must be done before printing the first time. 
f6

PRINT TEXT

f7 CAT

f8 END PROGRAM
Print the file on the printer select code from $\mathrm{f} 5$.

Print a catalog of specified disk.

Stop the program without saving the file.

In addition all the normal $\mathrm{H} / \mathrm{P}$ program editing keys may be used - insert line, delete line, insert character, delete character, and all the arrow keys.

\section{File Formats}

All files are ASCII files with data stored as strings. Each line in the file comprises one string and may contain an arbitrary number of items. All files are read using a free-field format; only the order of the data is important, not the position on any one line. Each item is separated from its neighbor by one or more spaces (usually one). For convenience we have adopted a convention of grouping several items on a line together to make it easier for the operator to "read" the file. For each file an example of actual data is given. Line numbers are shown for identification purposes only, they are not included in the file. The exact number of lines is unimportant; data may be stored all one line, or one item per line if desired.

\section{Runfiles}

Runfiles contain the measurement design data and commands to control operation of the READZEN program. The exact format will vary depending on the measurements required but will follow the general pattern of making cell measurements between the reference cell group and the Transfer Reference (DESIGN), measuring the unknown Zeners (ZMEAS), repeating the cell measurements (REDESIGN), and calculating the final results (ZCALC).

Note: The ten resistor voltages of the transfer reference are considered to be equivalent to cells for the purposes of the measurement programs and files. The ten voltages are assigned a group name of 'Zener' and individual IDs of Z1, Z2, Z3,..,Z10.

Sample data: RUNFILEA

$\begin{array}{ll}1 & 2.1138921114 \text { E11 Zener_workload } \\ 2 & \text { ! } 4 \times 10 \text { design, } 1600 \text { vs transfer Zener } \\ 3 & \text { DESIGN } \\ 4 & 216004 \text { Zener } 10 \\ 5 & 4010408165.4550 .034\end{array}$




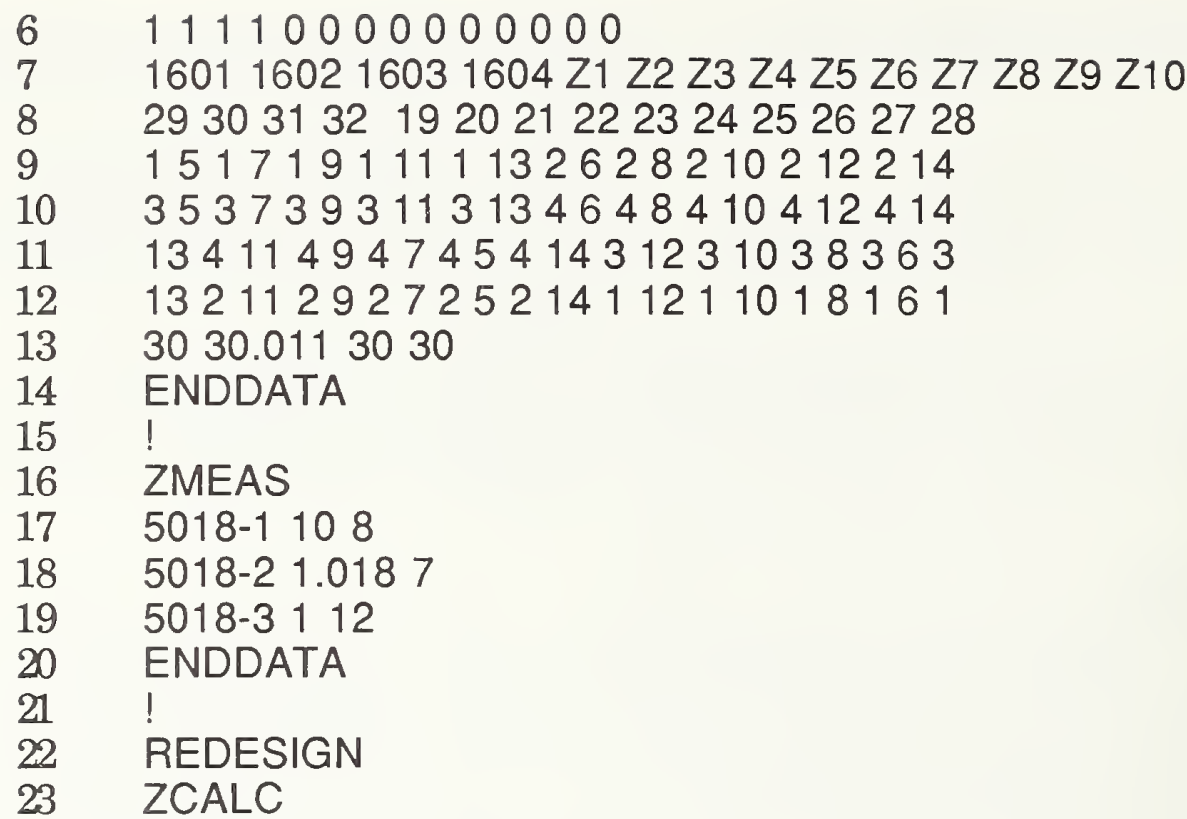

Description:

1 time and date in seconds (standard H/P time as returned by TIMEDATE), identifying label (up to 30 characters with no spaces) displayed by READZEN to identify different Runfiles

2 any line preceded by an exclamation point (!) is ignored by the program; this is a comment for the operator 3 command to the program to expect DESIGN data for intercomparing cell groups to follow

4 number of cell groups, group 1 name, number of cells in group 1, group 2 name, number of cells in group 2 a meaningless design number - not used but something must be there; total number of observations, mean of reference group, accepted standard deviation (the mean of the reference group is expressed in microvolts reduced by 1.01 volts, i.e., $8165.455 \int 1.018165455$ volts)

6 restraint - one number for each cell in each group, 1 identifies the cell as included in the mean of the reference group, 0 the cell is not included

$7 \quad$ cell IDs - group 1 first, group 2 next

8 cell circuit number corresponding to above cell IDs

9-12 measurement design - cells in line 7 are assigned position numbers 1 through $\mathrm{N}$ (14 here). Pairs of numbers indicate difference measurements to be made, i.e., 1 - 5 indicates to measure cell "1" (1601) minus cell "5" (Z1). The number of pairs of numbers must agree with the number of observations specified on line 5 . 
nominal temperature of group 1, actual temperature of group 1, nominal temperature of group 2, actual temperature of group 2

14 ENDDATA command to indicate end of DESIGN data set

15 comment

16

17-19 Zener ID, nominal voltage (volts), scanner channel

ZMEAS command to start accepting Zener measurement data for unknown Zeners to be measured number

20

ENDDATA command to indicate end of ZMEAS data set

21 comment

22

REDESIGN command, repeat previous cell intercomparison specified by the DESIGN data

23 ZCALC command, calculate standard cell measurement designs and final Zener voltages. ZCALC requires that a DESIGN measurement on the transfer reference be done before and after the ZMEAS measurements.

\section{"S" files}

"S" files contain the raw standard cell intercomparison data; only one set is shown here. A file may contain additional sets taken on the same day. The similarity between lines 4 through 12 of the Runfile with lines 2 through 10 of the "S" file is no coincidence!

Sample data: $S 860730$

$\begin{array}{llllll}2 & 2 & 1600 & 4 & \text { Zener } & 10 \\ 3 & 40 & 8165.455 & 0.034\end{array}$

$4 \quad 111110000000000000$

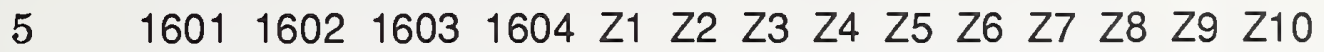

$\begin{array}{llllllllllllllllllllll}6 & 1 & 5 & 1 & 7 & 1 & 9 & 1 & 11 & 1 & 13 & 2 & 6 & 2 & 8 & 2 & 10 & 2 & 12 & 2 & 14\end{array}$

$\begin{array}{lllllllllllllllllllll}7 & 3 & 5 & 3 & 7 & 3 & 9 & 3 & 11 & 3 & 13 & 4 & 6 & 4 & 8 & 4 & 10 & 4 & 12 & 4 & 14\end{array}$

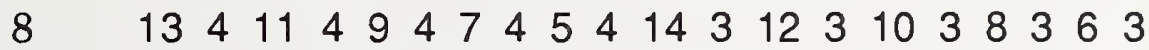

$\begin{array}{lllllllllllllllllllll}9 & 13 & 2 & 11 & 2 & 9 & 2 & 7 & 2 & 5 & 2 & 14 & 1 & 12 & 1 & 10 & 1 & 8 & 1 & 6 & 1\end{array}$

$10 \quad 30 \quad 30.011 \quad 30 \quad 30$

$\begin{array}{lllllll}11 & 157.742 & 199.267 & 87.808 & 173.733 & 173.267 & 149.658\end{array}$

$\begin{array}{llllllll}12 & 169.544 & 170.258 & 159.317 & 157.133 & 154.942 & 196.600\end{array}$

$\begin{array}{llllllll}13 & 84.825 & 170.825 & 170.467 & 151.842 & 171.758 & 172.492\end{array}$

$14 \quad \begin{array}{lllllll}161.475 & 159.417 & -169.067 & -169.608 & -83.544 & -195.217\end{array}$

$15 \quad-153.542 \quad-160.475-162.833 \quad-173.717 \quad-173.000 \quad-153.217$

$\begin{array}{lllllll}16 & -166.683 & -167.267 & -81.258 & -192.875 & -151.333 & -163.433\end{array}$

$17 \quad-165.633 \quad-176.592 \quad-176.000-156.083$ 
1 month, day, year, time, observer (system) name

2 number of cell groups, group 1 name, number of cells in

3 group 1, group 2 name, number of cells in group 2 total number of observations, mean of reference group, accepted standard deviation

4 restraint - one number for each cell in each group; 1 identifies the cell as included in the mean of the reference group, 0 the cell is not included

5 cell IDs - group 1 first, group 2 next

6 - 9 measurement design - cells in line 5 are assigned position numbers 1 through $\mathrm{N}$ (14 here) pairs of numbers indicate difference measurements to be made, i.e., 1 - 5 indicates to measure cell " 1 " (1601) minus cell "5" (Z1). The number of pairs of numbers must agree with the number specified on line 3.

10 nominal temperature of group 1, actual temperature of group 1, nominal temperature of group 2, actual temperature of group 2

$11-17$ actual measured cell differences in microvolts

"D" files

"D" files contain the results of the standard cell intercomparison data; only one set is shown here. A file may contain additional sets of data taken within the same week.

Sample data: DZEN_8630

$\begin{array}{lllllllllllll}1 & 860730 & 14 & 40 & 26 & 0.08247 & 0.0133 & \text { NBS-Z } & 12: 15: 11 & 2 & -0.596 \\ 2 & 1600 & 4 & 30 & 30.011 & -0.6226\end{array}$

Description:

1 YYMMDD, total number of cells, number of observations, degrees of freedom, standard deviation, left- 

right component, measurement system ID, time, number of cell groups, average DVM offset
group 1 name, number of cells in group 1, nominal
temperature, actual temperature, temperature cor-
rection
3
4
group 1 cell IDs
4 group 2 name, number of cells in group 2, nominal temperature, actual temperature, temperature cor- rection
$5-9$ group 2 cell IDs restraint flag, cell $\mathrm{ID}$, cell emf in $\mu \mathrm{V}$ reduced by $1.01 \mathrm{~V}$. The restraint flag $=1$ if the cell is included in the reference group mean, $=0$ if not. The restraint, ID, and emf triplet is repeated for each cell measured.

\section{"Z" files}

"Z" files contain the raw Zener measurements taken between the unknown Zener references and the transfer Zener; only one set is shown here. A file may contain additional sets taken on the same day.

Sample data: Z860730

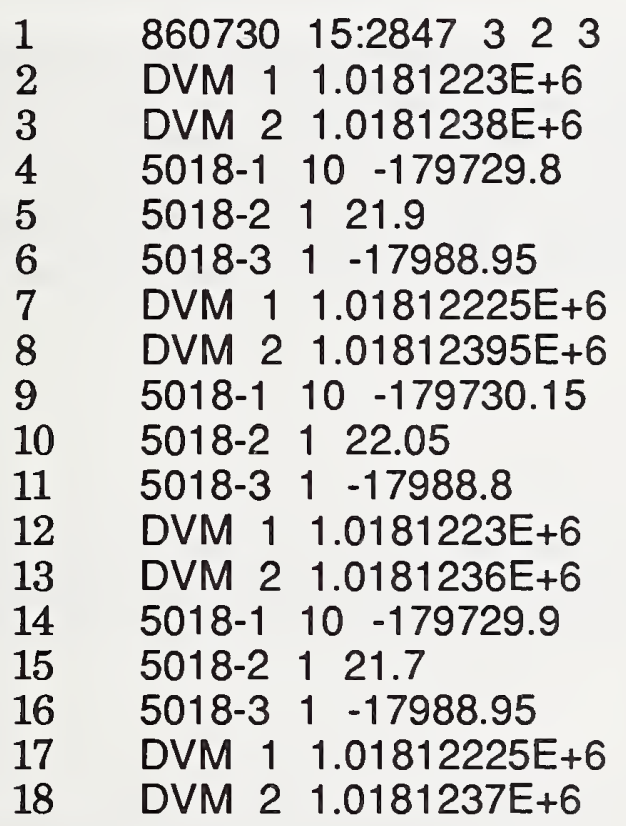

Description:

YYMMDD, time, number of repeated sets of Zener measurements, number of DVM calibrations per Zener measurement, number of Zeners measured 
2 - 3 string "DVM" to indicate a direct DVM reading of one of the resistors of the resistive divider, the number of the resistor measured (1-10), the reading in $\mu \mathrm{V}$

4- 6 Zener ID, tap number of resistive divider to which Zener was compared (0-10), measured difference in $\mu \mathrm{V}$

$7-18$ repeated measurements, stored the same as lines $2-6$

"R" files

" $R$ " files contain the final calculated results of the Zener data; only one set is shown here. A file may contain additional sets of data taken within the same week.

Sample data: RZEN_8632

$1860730 \quad 12: 53: 36 \quad 33$

$2448131.10001601 \quad 16021603 \quad 1604$

$3 \quad 5018-1 \quad 10.0000047045 \quad 0.00333333176584$

$4 \quad 5018-2 \quad 1.01799810104 \quad 0.142727802049$

$5 \quad 5018-3 \quad 0.9999895132710$

Description:

1

YYMMDD, time, number of Zeners calibrated, number of repeated measurements (Zsets)

2 number of reference cells, mean emf of reference cells, reference cell IDs

3-5 Zener ID, calculated voltage (volts), standard deviation of the mean (ppm) calculated from the repeated measurement sets

\section{System Software Requirements}

The measurement software will run satisfactorily on all $\mathrm{H} / \mathrm{P}$ Basic systems 3.0 and higher. The following BIN files are required for proper operation.

$\begin{array}{ll}\text { CLOCK } & \text { CS80 } \\ \text { KBD } & \text { MAT } \\ \text { ERR } & \text { HPIB }\end{array}$

For use with an SRM the following additional BIN files are needed. 
BIBLIOGRAPHIC DATA NBS/SP $-250 / 28$

2. Performing Organ. Report Nod 3. Publication Date

4. TITLE AND SUBTITLE

NBS Measurement Services: Solid-State DC Voltage Standard Calibrations

\section{5. $\operatorname{AUTHOR}(S)$}

Bruce F. Field

6. PERFORMING ORGANIZATION (If joint or other than NBS, see in structions)

7. ContracV/Grant No.

NATIONAL BUREAU OF STANDARDS

U.S. DEPARTMENT OF COMMERCE

GAITHERSBURG, MD 20899

8. Type of Report \& Period Covered Final

9. SPONSORING ORGANIZATION NAME AND COMPLETE ADDRESS (Street, City, State, ZIP)

Same as item 6 .

10. SUPPLEMENTARY NOTES

\section{Library of Congress Catalog Card Number 87-619904}

Document describes a computer program; SF-185, FIPS Software Summary, is attached.

11. ABSTRACT (A 200-word or less foctual summary of most significant information. If document includes a significant bibliography or literature survey. mention it here)

This document describes the procedures used at NBS to calibrate solid-state dc voltage standards in terms of the U.S. Legal Volt. The process involves calibrating client standards at NBS approximately 10 times over a two week period. The operational procedures and apparatus used to compare the client standards to the U.S. Legal Volt are discussed in detail.

12. KEY WORDS (Six to twelve entries: alphabetical order: capitalize only proper names; and separate key words by semicolons) calibration services; dc volt; solid-state standards; voltage standards; Zener diodes

\section{AVAILABILITY}

Unlimited

For Official Distribution. Do Not Release to NTIS

Ex] Order From Superintendent of Documents, U.S. Government Printing Office, Washington, D.C. 20402.

$\square$ Order From National Technical Information Service (NTIS), Springfield, VA. 2216I
14. NO. OF

PRINTED PAGES

39

15. Price 

SP 250-1 Spectral Radlance Calibrations

003-003-02792 \$3.50

SP 250-2 Far Ultraviolet Detector Standards $003-003-02810-0 \quad \$ 4.25$

SP 250-3 Radiometric Standards in the Vacurm Ultraviolet 003-003-02806-1 $\$ 6.50$

SP 250-4 Fricke Dosimetry In High-Energy Electron Beams 003-003-02816-9 \$2.75

SP 250-5 Alpha-Particle Callbrations

SP 250-6 Regular Spectral Transmittance 003-003-02805-3 \$3.25

SP 250-7 Radlance Temperature Callbrations 003-003-02827-4 \$2.25

SP 250-8 Spectral Reflectance $003-003-02812-6 \quad \$ 7.00$

SP 250-9 Callbration of Beta-Particle-Emilting Ophthalmic Applicators $003-003-02817-7 \quad \$ 2.00$

SP 250-10 Radioactivity Callbrations with the "4 $\pi$ " Garmma Ionization Chamber, and Other Radioactivity Callbration Capabilitiles 003-003-02824-0 \$2.25

SP 250-11 Dosimetry for High-Dose Applications

SP 250-12 Neutron Personnel Dosimetry 003-003-02811-8 $\$ 2.50$

SP 250-13 Activation Foll Irradlation with Calfornlum Fission Sources

SP 250-14 Activation Foll Irradiation by Reactor Cavity Fission Sources
SP 250-15 Photometric Callbrattons

SP 250-16 Callbration of X-Ray and Gamma-Ray Measuring Instruments

SP 250-17 The NBS Photodetector Spectral Response Callbration Transfer Program

SP 250-18 Neutron Source Strength Calibrations

SP 250-19 Callbration of Gamma-Ray-Emitting Brachytherapy Sources

SP 250-20 Spectral Irradlance Callbrations 003-003-02829-1 $\$ 5.50$

SP 250-21 Callbration of Beta-Particle Radiation Instrumentation

SP 250-22 Platinum Resistance Thermometer Callbrations 003-003-02831-2 $\$ 17.00$

SP 250-23 Liquid-In-Glass Thermometer Callbration Service

SP 250-24 Standard Cell Callbrations $003-003-02825-8 \quad \$ 2.75$

SP 250-25 Callbration Service for Inductive Voltage Dividers

SP 250-26 Phase Angle Calibrations

SP 250-27 AC-DC Difference Calibrations

SP 250-28 Solld-State DC Voltage Standard Calibrations

SP 250-29 Traceable Frequency Callbrations

SP 250-30 GOES Satellite TIme Code DIssemination: Description and Operation

* Those entries containing a stock number (003-003--) and price can be purchased from the Superintendent of Documents, U.S. Government Pinting Office, Washington, DC 20402. GPO will accept checks, money orders, VISA, and Mastercharge. For more Information, of to place an order, call (202) 783-3238. Be sure to use the stock number In all orders. Titles without stock numbers are In preparation. 
U.S. Department of Commerce National Bureau of Standards

Gaithersburg, MD 20899

Official Business

Penalty for Private Use $\$ 300$ 